\title{
A case report on aggressive fibromatosis of the arm and shoulder
}

\author{
Sameh Hany Emile, Ahmad Sakr \\ Department of General Surgery, Mansoura Faculty of Medicine, Mansoura University, Egypt
}

Received: October 26, 2020

Accepted: December 31, 2020 Online Published: January 3, 2021

DOI: $10.5430 /$ dcc.v $7 \mathrm{n} 4 \mathrm{p} 1$

URL: https://doi.org/10.5430/dcc.v7n4p1

\begin{abstract}
Background: Aggressive fibromatosis is a locally aggressive tumor that originates from the deep musculo-aponeurotic structures. In this report, we describe the case of an adolescent male with painless, progressively growing swelling in his right arm necessitated surgical excision and postoperative pathologic examination revealed aggressive fibromatosis.

Case presentation: A 15-year-old boy presented with a painless, progressively growing swelling of his right arm. The swelling was firm, non-tender and with restricted mobility. MRI imaging revealed a well-defined, heterogenous, lobulated swelling extending beneath arm and shoulder muscles. Wide local excision of the swelling was done under general anesthesia and pathologic examination revealed aggressive fibromatosis of the arm. Adjuvant radiotherapy was provided to the patient to reduce the risk of local recurrence of the tumor.

Conclusion: Aggressive fibromatosis of the upper limb presents as a painless, progressively growing swelling. Assessment with MRI is imperative for making a preliminary diagnosis. Wide local excision with safety margin with adjuvant radiotherapy is the main line of treatment to minimize the incidence of recurrence and preserve the limb.
\end{abstract}

Key Words: Aggressive, Fibromatosis, Arm, Shoulder, Case report

\section{INTRODUCTION}

Desmoid tumors are soft tissue neoplasms that account for approximately $3 \%$ of all soft tissue tumors with an annual incidence $0.2-0.4$ for every 100,000 individuals. Also known as aggressive fibromatosis, these tumors originate from the deep musculo-aponeurotic structures. ${ }^{[1]}$ Desmoid tumors are classified as intra-abdominal, abdominal wall, or extraabdominal, with the extra-abdominal type being the most common, accounting for about one-third of all desmoid tumors. The commonly reported affected sites by desmoid tumors are the shoulder girdle, abdominal wall, chest wall, breast, abdominal mesentery, and pelvis. ${ }^{[2]}$

Desmoid tumors have unusual biology and are locally ag- gressive but never metastatic, hence they are classified to be of intermediate behavior using the WHO classification of soft tissue neoplasm. ${ }^{[3]}$ With its tendency for aggressive infiltration of local structures, the differentiation between fibromatosis and low-grade fibrosarcoma can be difficult. ${ }^{[4]}$

In this report, we describe the case of an adolescent male with painless, progressively growing swelling in his right arm necessitated surgical excision and postoperative pathologic examination revealed aggressive fibromatosis.

\section{Case presentation}

A 15-year-old male patient presented with a painless, progressively growing swelling in his right arm for the last six

\footnotetext{
*Correspondence: Sameh Hany Emile; Email: sameh200@hotmail.com; Address: General Surgery Department, Faculty of Medicine, Mansoura University Hospitals, Elgomhuoria Street, Mansoura city, Egypt.
} 
months. The patient described the swelling to be of a gradual onset. The swelling was not painful, yet caused a sensation of discomfort on elevation of the right arm. On clinical examination a $10 \mathrm{~cm} \times 7 \mathrm{~cm}$ swelling was felt at the radial aspect of the upper arm, extending upwards to the shoulder. The swelling was firm in consistency, non-tender, well-defined, and with restricted mobility (see Figure 1).

MRI imaging of the right upper limb (see Figure 2) revealed a $12 \mathrm{~cm} \times 6 \mathrm{~cm}$, well-defined, heterogenous, lobulated soft tissue mass at the lateral aspect of the upper arm. The mass extended beneath the triceps muscle, upwards beneath the deltoid muscle. Tru-cut biopsy was taken and pathologic examination revealed a spindle-shaped tumor, mostly a schwannoma.

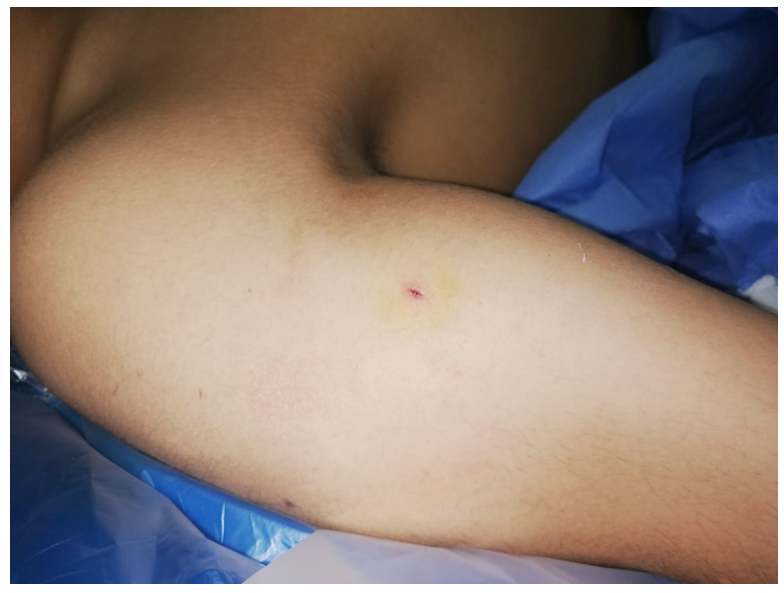

Figure 1. Clinical image of the swelling in the right arm

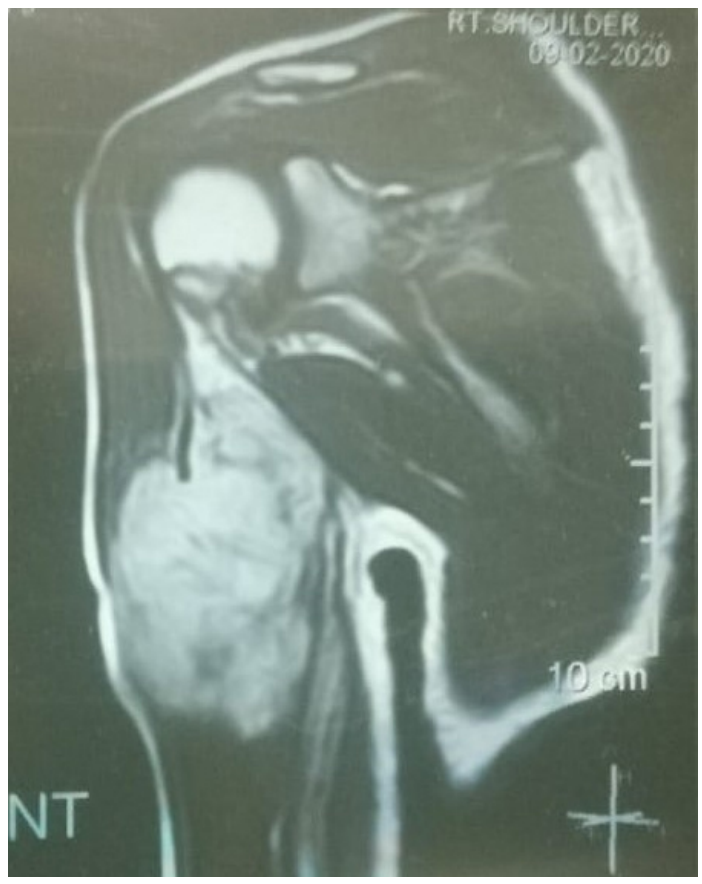

Figure 2. MRI of the right arm swelling
The patient underwent surgery for excision of the swelling under general anesthesia. A 10-cm longitudinal incision was made along the swelling and dissection was carried out with electrocautery. A firm swelling was found lateral to the triceps muscle and extending beneath the muscle, firmly adherent to the humerus. The swelling was traced upwards beneath the deltoid muscle as demonstrated in the MRI imaging. The swelling was dissected from the surroundings and was excised with electrocautery from the lateral to the medial aspects. On dissection of the medial part of the swelling, it was found in close proximity to the brachial artery and median nerve which were preserved and then the swelling was completely excised (see Figure 3).

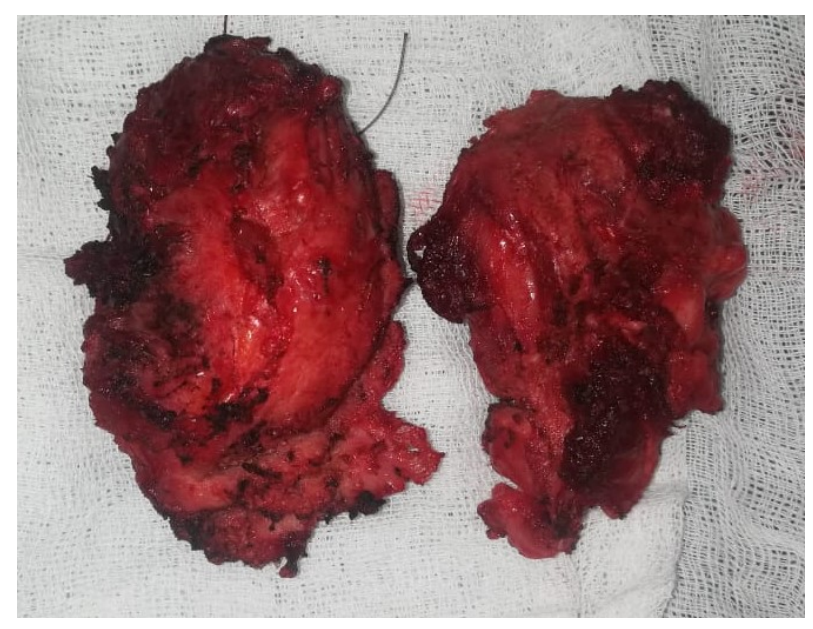

Figure 3. The arm swelling upon its excision

Hemostasis was ascertained then a suction drain was placed in the wound which was closed in layers. Postoperative recovery was uneventful except for slight wrist drop that was investigated with radial nerve conduction study which revealed transient neurapraxia of the radial nerve.

Postoperative histopathologic examination of the excised swelling reveled aggressive fibromatosis of the arm and shoulder with infiltrated safety margins. Immunohistochemical staining for $\beta$-Catenin confirmed the diagnosis of Desmoid-type fibromatosis. The patient was referred to radiotherapy department to receive adjuvant sessions of radiation therapy to decrease the incidence of recurrence of the tumor.

\section{DISCUSSION}

The patient of this report was an adolescent boy, in contrast to the current literature in which desmoid tumors are more commonly found in women with a female to male ratio of $2: 1$. The age of the patients ( 15 years) was within the range of affection by desmoid tumors, between the ages of 10 and 40 years. $^{[5]}$ 
There was no history of trauma or hereditary conditions in the family of the patient of the present report. Desmoid tumors are often of idiopathic nature, however they can be associated with pregnancy, trauma, surgery and hereditary cancer syndromes such as familial adenomatous polyposis (FAP) in which the desmoid tumor becomes very aggressive. ${ }^{[6]}$

The onset and character of the arm swelling in the present report warranted further assessment using MRI that showed a soft-tissue mass with suspicious features as being lobulated and heterogenous. Preoperative biopsy was then decided to reveal the nature of the swelling. However; the outcome of preoperative biopsy did not coincide with the final histopathologic diagnosis which castes shadows of doubt on the accuracy of this investigation.

There is no standard treatment for desmoid tumor until now. Where possible, wide local excision with adequate safety margin should form the cornerstone of fibromatosis treatment. ${ }^{[7]}$ In spite of this, local recurrence is not guaranteed. The patient was scheduled to surgery and wide local excision of the swelling was indicated. The swelling was rather difficult to excise owing to its location beneath the triceps and deltoid muscles and also because its medial aspect was in close proximity to the main arterial supply of the arm and forearm, which may explain the infiltrated safety margins

\section{REFERENCES}

[1] Reitamo JJ, Hayry P, Nykyri E, et al. The desmoid tumor. I. Incidence, sex, age and anatomical distribution in the Finnish population.Am J Clin Pathol. 1982; 77: 665-673. PMid:7091046. https : //doi.org/10.1093/ajcp/77.6.665

[2] Corsten M, Donald P, Boggan J, et al. Extra abdominal fibromatosis (desmoid tumor) arising in the infratemporal fossa: a case report. Skull Base Surg. 1998; 8(4): 237-241. PMid:17171074. https://doi.org/10.1055/s-2008-1058191

[3] Papagelopoulos PJ, Mavrogenis AF, Mitsiokapa EA, et al. Current trends in the management of extra abdominal desmoid tumors. World J Surg Oncol. 2006; 4: 21. PMid:16584569. https : //doi.org/10.1186/1477-7819-4-21

[4] Posner MC, Shiu MH, Newsome JL, et al. The desmoid tumor. Not a benign disease. Arch Surg. 1989; 124: 191-196. PMid:2916941. ht tps://doi.org/10.1001/archsurg.1989.01410020061010 on pathologic examination. It would have been helpful to have the excised swelling examined intraoperatively using frozen section pathology. However, since this was not readily available in the operating theatre it was not performed.

Other lines of treatment of Desmoid tumors include, radiotherapy, chemotherapy, hormonal treatment and nonsteroidal anti-inflammatory drugs which represent a recent paradigm shift in the management of desmoid tumors. ${ }^{[8]}$ The patient was indeed referred for postoperative adjuvant radiotherapy in attempt to reduce the incidence of local recurrence of the swelling, especially with the infiltrated safety margins detected.

\section{Conclusion}

Aggressive fibromatosis of the upper limb presents as a painless, progressively growing swelling. Assessment with MRI is imperative for making a preliminary diagnosis. Preoperative biopsy, albeit being indicated in the majority of cases, may not reveal the underlying pathology accurately. Wide local excision with safety margin with adjuvant radiotherapy is the main line of treatment to minimize the incidence of recurrence and preserve the limb.

\section{CONFLICTS OF INTEREST Disclosure}

The authors declare they have no conflicts of interest.
[5] Escobar C, Munker R, Thomas JO, et al. Update on desmoid tumors. Ann Oncol. 2012 Mar; 23(3): 562-569. PMid:21859899. https://doi.org/10.1093/annonc/mdr386

[6] Molloy AP, Hutchinson B, O’Toole GC. Extra-abdominal desmoid tumors: a review of the literature. Sarcoma. 2012; 1-9. PMid:22966217. https://doi.org/10.1155/2012/578052

[7] Pajares B, Torres E, Jim enez B, et al. Multimodal treatment of desmoid tumors: the significance of local control. Clin Transl Oncol. 2011; 13: 189-193. PMid:21421464. https://doi.org/10.100 7/s12094-011-0639-4

[8] Eastley N, Aujla R, Silk R, et al. Extra-abdominal desmoid fibromatosis-a sarcoma unit review of practice, long term recurrence rates and survival. Eur J Surg Oncol. 2014; 40(9): 1125-1130. PMid:24612653. https://doi.org/10.1016/j.ejso.2014.02 .226 